on the extremities very yellow and re-1 markably developed. From the 12th day the eruption gradually subsided, and as soon as was prudent, warm-baths were used.

Thus while all appeared to go on well, the tender surface of the lower extremities began to discharge a serous fluid, which, upon minute inspection, was found to proeeed from small vesicles, forming in their progress from their humid to their dry incrusted state, all the characteristics of eczema rubrum. This affection proceeded afterwards to the back, arms, shoulders, and head. And this again was soon followed by rupia, the bullæ arising, principally, on the legs and thighs; and, progressively a few about the radii, neck and loins; some advancing to suppuration, and others receding previous to reaching the purulent state. The child has just recovered, and is slightly marked by the small-pox.

C AsE II. - Andiew Laffey, aged two years, son of an Lrish labourer, residing in King's Gardens, Gravel-lane, was recommended to my notice while attending the former case, and has since been under my eare at the City Dispensary. In that district the small-pox was then prevalent, and Laffey's parents, frightened by the mortality it produced among their neighbours, bastened to the Institution at Surrey Chapel, on Tuesday (6th Nov.), and had him vac. cinated. The vaccine took remarkably well, and went on in the most regular and perfect manner through all its stages. On Sunday, however, the child became sick ; on Monday he had much fever, lassitude. \&c. On Tuesday (the eighth day after vaccination) the variolic eruption became general. Still the vaccine went on unimpeded in its progress, the ulcers, particularly those on the left arm, producing much uneasiness by their united and intense iuflammation. Át this period the case was seen by Mr. Odling, surgeon, in Union-street, and by another member of the profession.

I'he small-pox now continued its regular course, and, whether modified or not by the vaccination, was very severe, and did not take the turn before the twelfth or thirteenth day. After the variolic eruption had become dry, and the skin nearly cleared of that substance, the eczema, as stated in the first case, but unaccompanied by rupia, broke out all over the body, proceeding, in like manner, from the lower extremities to the head. At the same time, one of the vaccine ulcers, large enough to admit a good sized pea, remained open for many weeks, with much chronic hardness around it, dis. charging a limpid fluid, which raised the surrounding epidermis, after the manner of cantharides. 'The child is now well, and bears, at once, indelible marks of small-pox on his face, and of vaccination on his arm.
OBJECTHONS TO MR * COW'S

CAOUTCHOUC FRACTURE BAG,

WITH A DESCRIPTION OF A

NEW MODE OF TREATING FRACTURED LIMBS.

To the Editor of The Lancet.

Sra,-As your LANCET is the channel through which much useful professional iuformation weekly flows, I beg to request that you will, through its medium, gire publicity to the following new mode of treating fractured limbs. I am, Sir, your obedient servant and constant reader,

JoHn Brown, C. M. Assist.-Surgeon Royal Nary.

8, Samuel-street, Woolwich, Jan. 1, 1833.

About a year and a half ago, an apparatus, for the cure of fractures, was invented. by a person of the name of Cow, a foreman of sbipwrights in Woolwich dock-yard, and sent to the different naval hospitals for trial by order of the Board. To this apparatus, which is merely a sort of bag, made of caoutchouc, and filled with air, I have lately paid considerable attention, and have found so many objections to its use, that every scientific man must, I think, at first sight, clearly perceive, that it never can answer the purpose for which it is intended. The idea, however, of curing fractures by means of an inflated apparatus, which, at the time I first saw Mr. Cow's bandage, made an impression on my mind, has since led me to think of a method by which the principle may, I conceive, be advantageously applied to that important part of practical surgery. Before 1 proceed, however, to give a detail of this plan, I shall take the liberty of mentioning a few of the objections which I have to Mr. Cow's new fracture bandage, as he calls it.

In the case of an oblique fracture of the middle of the femur, this apparatus of his, which completely surrounds the whole of the thigh, from the groin down to the knee, but which does not reach the superior extremity of the bone, makes, when inflated, equal pressure over the whole of the surface it covers. Now this must certainly prove hurtful, because the injured part is compressed all round, and the muscles are forced upon the fractured ends of the bone, which, of course, must irritate them, cause pain, and, in some cases, inflammation and swelling, while such pressure can have no tendency whatever to prevent the inferior end of the broken bone from being drawn up by the irrilated muscles, unless, indeed, it be so great as to impede the circulation of 
the blood through the limb, and so prevent that healthy action from going on, which is necessary for the formation of callus, and the firm consolidation of the fracture. Even in cases where the bone is broken transversely, I doubt much if Mr. Cow's apparatus will often succeed in effecting cures without deformity. The lind of compression it makes, can never afford that steady support to the whole limb, which a firm splint, pressing on the knee-joint, and extending to the great trochanter, will give; so that from st:rting, or any other kind of motion. the thigh, I think, will frequently become bent. I offer this only as an opinion, but it appears to me to be quite plain, that when the femur is fractured obliquely, this bandage will have a tendency to cause, ra. ther than to prevent, longitudinal displacement. An air-tight apparatus, like the one in question, put round the whole of a limb, will also interfere with the action of the cutaneous vessels. The perspiration, which cannot in any way escape, must, of course, accumulate, become acrid, and frequently cause great uneasiness by irritating the skin. The heat, too, must be increased, and cold lotions cannot be applied with any benefit to a part so surrounded. Upon the whole, then, I think, that after the charm of novelty has faded, Mr. Cow's apparatus will be found to be butill calculated to cure fractures of the os femoris, particularly if they be oblique, without deformity of the limb.

Having stated these objections, I shall endeavour to describe the manner in which I think the inflated caoutchouc may be advantageously used in the cure of oblique fractures of the thigh. The apparatus $I$ have invented, acts on the principle of extension and counter-extension, like the celeorated Desault's, and consists of three splints of a peculiar construction, two broad linen bands, and an eighteen-tailed bandage. One of these splints, morticed and niched at its extremities, exactly like Desault's, extends from the ridge of the os ilium to a little distance beyond the sole of the foot, on the outside of the leg, and another from the groin to the ankle, on the inside, and the third from the hip to the calf of the leg, posteriorly. Nothing is put on the anterior part of the thigh ; indeed I have often wondered why Desault placed a splint in that situation and none behind, for the extended position of the leg must of course relax the muscles on the anterior part of the thigh, while those on the posterior will, for the same reason, be put on the stretch; and I do not think that the bed on which the patient lies, can of itself have much effect in moderating the action of those powerful muscles. The caoutchouc, covered with cloth, and having infating tubes attacled to it, is fixed to the internal surface of each of these splints, allowing. it to project about an inch past the edges, and to extend, longitudinally, to the extremities of the posterior and internal lateral, but only to the mortice holes of the external, that it may not inter. fere wich the bands, the action of which is to cause extension and counter-extension of the leg and thigh. The external and in. ternal splints are connected anteriorly and posteriorly by means of short pieces of tape, but the one which is put on the back part of the thigh is altogether detached, and must he inflated before it is put in its place, where it is supported by the posterior tapes of the lateral splints within which it lies.

This apparatus, which, in some respects, so much resembles Desault's, may be applied in the following manner, in one balf the time that will be required by any one to fix Desault's :- the middle of the eighteen-tailed bandage is first laid over the detached splint; one of the bands is then put over the inside of the thigh, close to the groin, its ends carried outward and upward, passed through the mortice, and tied over the niche on the superior extremity of the external splint. The lower band is put round the leg, over the instep, and under the foot, in the same way as Desault's. One end is then pushed through the mortice, and the other laid over the niche, but they are not tied. Extension and counter-extension are now made in the usual way, and the surgeon takes hold of the thigh, and puts the fractured ends of the bone into apposition. As soon as this is done, the external splint is inflated by an assistant, and the ends of the iuferior band are drawn tight, and firmly tied, by which the leg is pulled down, and extension made, while the splint is, at the same time, pushed up, and counter-extension effected by the band at the groin. The ends of the many -tailed bandage are next crossed on the anterior part of the thigh, from the patella to the groin, the internal splint brought into its place, and the anterior tapes tied. This splint is then inflated, so that the whole of the hollows, both on the outside and inside of the thigh and leg, are perfectly filled up, and the projections, as the ancles, knee-joints, and great trochanter, rest upon an elastic nuid, which accurately adapts itself to the formation of those parts. and prevents the splints from irritating them in any way by their pressure. Such a degree of extension and counter-extension is kept up, as soon weakens the disposition in the muscles to contract, and, at the sane time, the leg and thigh are so firnly sup. ported, that $I$ have no doubt a patient mar, if necessary, be moved from one place to another, without any risk of the fractured ends of the bone being dieplaceri. The 
eighteen-tailed bandage may be undone and reapplied as often as necessary, with. out disturbing the limb, which is a great adrantage. No hurtful pressure is ever. made on the fractured part. 'The healthy action of the limb goes on, and if, at any time, swelling should take place, and the apparatus become too tight, all that is required to remedy this evil, is merely to allow a sufficient quantity of air to escape, by turning the screw of one of the splints, and, as soon as the swelling diminishes, any degree of pressure can again easily be made $\mathrm{by}$ increasing the inflation-in short, the advantages which this apparatus pos. sesses, appear to me to be so great, that if it receive a fair trial, I have no doubt it will be found to be a vast improvement on that which was, at one time, so successfully used by Desault in the cure of oblique fractures of the femur. If the two oblique planes, or fracture box, recommended by Mr. C. Bell, be preferred by any one, then these splints, made of the proper length, will render that plan both more easy and more efficient.

With regard to simple fractures of both bones of the ley, it is not very often that so snuch difficulty is experienced in curing them without deformity, because the muscles are not so strong as those of the thigh, and in such cases I think Mr. Cow's apparatus may sometimes succeed, particularly if the leg be bent and laid upon its side; but still its use is objectionable, for, as it covers the whole of the leg and foot, it must interfere with the action of the cutaneous vessels, as before mentioned, rudely press the muscles against the rough ends of the broken boue, increase the heat, and prevent the use of cold applications, so that the object which the surgeon has in view may, 1 think, even in such cases, be more easily accomplished in the old wav, by means of common splints, which, if well made and properly applied, are free from the above objections. Mr. Cow has, how ever, I believe, at the suggestion of a medi. cal man, made detached pieces of caoutcliouc for the $1+0$; but is they have no firmness in them, except what is caused by their inflation, they cannot give sufficient support to the extremities of the bone, and therefore cannot be used, with advantage, in cases of fracture.

The splints, which I have now beside me for fractures of the leg, are two in number. They extend from the knee-joint to a little distance beyond the ankle, have the caoutchouc attached to their internal surfaces, and are applied, in the usual way, to the outside and inside of the leg. When the fractured ends of the bone have been properly placed, these splints are inflated, which at once puts sufficient pressure on the knee and ancle joint $\$$, and, at the same time, gives such a degree of support to the whole limb, as cannot be obtained by any other plan with which I am acquainted. I shall only add, that all of the above-mentioned splints are so made, that they can be filled with water instead of air, at the pleasure of the surgeon.

J. B:

\section{LONDON PHRENOLOGICAL SOCIETY.}

Monday, January 7 th, 1833.

\section{Professor Elilotson, President.}

Mr. George Frankur, Surgeon, of Lisson Grove, and Mr.J. G. Graeff, of Fur. nival's Inn, were elected members of the Society.

\section{HU}

Mr. Mrtier, analomy modeller, exhibited a mould in wax, made from the head of the monkey termed the Chimpansee, the near approach of which to the form of the human head, was remarkable. The cranium and face approximated in an astonishing degree in appearance to the baked heads of the New Zealand chiefs occasionally shown in this country. The President observed, in fact, that the Chimpanzee came nearest in conformation of all monkeys to the human race. It has no intermaxillary bone, has nails on its hind thumbs, and a ligamentum teres at the head of the thigh-bone. The present Chimpanzee was brought to England from Borneo, in rum, having died on the voyage. It was purchased of the captain. by Mr. Iangstaff, who now possesses the skeleton. The head of this auimal probably assimilated more closely to that of man, than that of any Chimpanzee hitherto brought to this country.

Mr. Whitwer presented a copper-plate to the members, on which a medallion head. of Gall was beautifully engraved by the new copying machine, to be used for the ad. mission tickess of the Society.

BIOGRAPHICAL PAPFR ON THE CHARACTTR AND PIIRNOLOGICAL ORGANIZATION OF DR. SPURZHLIT.

The Marquis Moscatr then presented the following paper to the Society, which was immediately real, and afterwards reeeived the thanks of the members. Casts of the head of Gall, Spurzheim, and Smithers, were on the table. 